\title{
BMJ Open Incidence, morbidity and mortality of hip fractures over a period of 20 years in a health area of Southern Spain
}

\author{
Marta M Rey-Rodriguez (D) , ${ }^{1}$ MA Vazquez-Gamez (D) ,, Mercè Giner (D) , ${ }^{3}$ \\ Fernando Garrachón-Vallo, ${ }^{4}$ Luis Fernández-López, ${ }^{4}$ Miguel Angel Colmenero, ${ }^{4}$ \\ María-José Montoya-García (iD ${ }^{2}$
}

To cite: Rey-Rodriguez MM, Vazquez-Gamez MA, Giner $\mathrm{M}$, et al. Incidence, morbidity and mortality of hip fractures over a period of 20 years in a health area of Southern Spain. BMJ Open 2020;10:e037101. doi:10.1136/ bmjopen-2020-037101

- Prepublication history for this paper is available online. To view these files, please visit the journal online (http://dx.doi. org/10.1136/bmjopen-2020037101).

Received 22 January 2020 Revised 23 July 2020 Accepted 13 August 2020
Check for updates

(C) Author(s) (or their employer(s)) 2020. Re-use permitted under CC BY-NC. No commercial re-use. See rights and permissions. Published by BMJ.

${ }^{1}$ Servicio Medicina Interna, Hospital Viamed Santa Angela de la Cruz, Sevilla, Spain ${ }^{2}$ Medicine Department, Universidad de Sevilla Facultad de Medicina, Sevilla, Spain

${ }^{3}$ Citología e Histología Normal y Patológica, Universidad de Sevilla Facultad de Medicina,

Sevilla, Spain

${ }^{4}$ UGC Medicina Interna, Hospital Universitario Virgen Macarena, Sevilla, Spain

Correspondence to

Dr Mercè Giner; mginer@us.es

\section{ABSTRACT}

Objective To evaluate the incidence of osteoporotic hip fracture in the Macarena Health Area (Seville).

Setting and participants This was a prospective observational study that collected all osteoporotic hip fractures that occurred between March 2013 and February 2014 at the Clinical Unit of Traumatology and Orthopaedics. All cases collected during the first 6 months of the study were followed for 1 year after the occurrence of the event.

Outcome measures We evaluated the incidence of osteoporotic hip fractures in the Macarena Health Area (Seville) from 1 March 2013 to 28 February 2014, and we compared the incidence with that in 2 previous studies carried out with the same methodology in 1994 and 2006. Furthermore, we calculated the morbidity and degree of disability 1 year after the fracture occurred and determined mortality and the associated factors.

Results The overall incidence was 228 per 100000 individuals/year (95\% Cl 204.5 to 251.6), and the incidence was higher in women than in men. In women, the incidence rate decreased in all age groups over time, while in men, the incidence rate increased. The mortality rate 1 year after the episode was $27.2 \%$. The factors associated with overall mortality were a body mass index below $25 \mathrm{~kg} / \mathrm{m}^{2}$, renal failure and low plasma proteins. Conclusions Our results show a high incidence of osteoporotic hip fracture that is increasing in men, and in men it is associated with a higher mortality than in women. There is room to improve the modifiable factors associated with mortality and the available rehabilitation interventions to reduce the disability associated with these fractures.

\section{INTRODUCTION}

Hip fractures are a critical public health problem due to their incidence and individual and societal repercussions. Globally, the incidence of hip fractures increases as the population ages; over 8 million hip fractures worldwide are expected in 2050. ${ }^{1}$ In terms of consequences, fractures are greatly associated with disability. Based on data from the literature, it has been estimated that $32 \%-80 \%$ of those who survive the initial hospitalisation

\section{Strengths and limitations of this study}

- First study analyses the evolution of the incidence of osteoporotic hip fracture over 20 years in the South of Spain.

- This study has a prospective cohort design with active follow-up during the subsequent 12 months for the evaluation of disability and mortality.

- A limitation of the study is that only the cohort of patients evaluated in the first 6 months were followed to estimate mortality and degree of disability.

- We could not add the Charlson Comorbidity Index, which could have improved the analysis.

after a hip fracture will suffer from permanent disability and $17 \%$ will be admitted to long-term care facilities due to the fracture. ${ }^{2}$ Moreover, the mortality rate 1 year after hip fracture has been reported to be $20 \%$ in women and $26 \%$ in men. ${ }^{3}$ Furthermore, hip fractures are associated with significant costs, especially those due to hospitalisation, outpatient and home care, and rehabilitation. ${ }^{2-4}$

Hip fractures are considered a good proxy variable to assess the burden of osteoporosis because they are responsible for the majority of health costs related to fractures and mortality in people $\geq 50$ years old, although hip fractures represent less than $20 \%$ of osteoporotic fractures. ${ }^{5}$ To establish health programmes for the prevention and treatment of both the acute process and its complications, it is necessary to understand the current situation and evolutionary trend of this problem through epidemiological studies. Although several studies have recently been conducted on the epidemiology of hip fractures and their temporal trends ${ }^{6}$ in Spain both at the national level ${ }^{78}$ and in specific geographical areas, ${ }^{9-12}$ few studies have evaluated the temporal trends associated with these fractures, the resulting short-term and longterm mortality, and the disabilities of those 
who survive. On the other hand, both international and national studies have shown that this temporal trend in incidence can vary greatly from one country or region to another. ${ }^{6}{ }^{13}$ In a systematic review that assessed the worldwide incidence of hip fractures, the incidence observed in countries with the highest rates was 10 times higher than in those with the lowest rates. ${ }^{5}$ A study conducted in Spain using the Minimum Basic Data Set also showed that the temporal incidence trend varies from one region to another. ${ }^{8}$ Therefore, it is important to conduct both national and regional studies evaluating this health problem. The main objectives of this prospective observational study were to evaluate the incidence of osteoporotic hip fracture in the Macarena Health Area (Seville) and its evolution over the last 20 years and to study the characteristics of the affected population. Furthermore, we sought to assess the morbidity and degree of disability 1 year after the fracture and to determine the in-hospital mortality and mortality rates 1 year after the fracture and the associated factors.

\section{METHODS}

\section{Design, scope and case definition}

This was a prospective observational study that collected all osteoporotic hip fractures of the Virgen Macarena Hospital Area (Seville) that occurred between 1 March 2013 and 28 February 2014, in patients of the Traumatology and Orthopaedics Clinical Unit. All cases collected during the first 6 months of the study were followed for 1 year after the event.

Informed consent was obtained from all participating subjects.

An incident case of osteoporotic hip fracture was considered if it met the following criteria: occurred in a subject $\geq 50$ years old; was radiologically verified and occurred spontaneously or as a result of minor trauma without acceleration from the patient's own height and without another medical cause that would justify and identify the fracture as pathological. All cases that occurred during the study period were included regardless of whether the subjects were admitted to the hospital, kept under emergency observation, were transferred to another hospital, discharged or died. The patients whose fracture occurred in the first 6 months of the study were re-evaluated after 1 year; however, the patients who presented with fracture in the last 6 months of the study were referred for follow-up with their primary care physician, and we do not know their final outcome (figure 1).

To avoid missing data, the data of patients admitted for hip fracture were reviewed from two sources: the information provided by the records of the emergency department and the records of the Traumatology and Orthopaedics Department. To avoid duplications, if the same patient record appeared throughout the study period because of another consultation, the patient was evaluated to exclude a complication of the initial episode (eg, pain, periprosthetic fractures, infection dislocation) and confirm a new episode of hip fracture. The patients who were not admitted to the hospital the information was obtained by telephone.

\section{Patient and public involvement}

No patients were involved.

\section{Evaluations}

Based on the medical records, discharge reports and patient interviews, the following data were collected: demographic data, anthropometric data (the height and weight data were collected by anaesthetists), number of falls during the year prior to the fracture, toxic habits, associated diseases and chronic drug treatments. The analytical parameters were collected within the first 24 hours after the fracture episode. Fracture-related data included the date, type of fracture and risk factors (calculations of the probability of hip fracture 10 years before and immediately prior to the fracture using the Fracture Risk Assessment Tool (FRAX) score ${ }^{14}{ }^{15}$ physical activity prior to the fracture, history of previous fractures, time to surgery and length of hospital stay). Regarding the consequences of the fractures, data were collected on in-hospital complications, in-hospital mortality, mortality 1 year after the episode, and sequelae and events during the year following the fracture. Finally, at the time of the clinical interview, the patients were evaluated with the abbreviated version of Mini Nutritional Assessment (MNA), which classified patients as possibly malnourished when the score is $\leq 11$ points. ${ }^{16}$ Based on the information obtained at the time of the fracture and 1 year after the fracture, the modified Barthel Scale ${ }^{17}$ was also applied; individuals with a score $\geq 6$ were considered dependent. Additionally, changes in independence/autonomy were reflected by residence status, activities of daily living, physical activity and need for walking assistance.

\section{Statistical analysis}

The annual incidence of hip fractures per 100000 individuals and the associated $95 \%$ CI were estimated with absolute values and adjustments for age and sex. In the calculation, the numerator reflected all cases according to the definition above, and the denominator reflected the reference population aged $\geq 50$ years served by the Virgen Macarena Hospital, which included 157428 people as of December 2013 according to the database of the Healthcare Area of the Hospital Virgen Macarena. To compare the 20-year trend, we used the results of studies from the same geographical area with similar methods. ${ }^{18}$ We used a study conducted between June 1994 and May 1995 (hereafter referred to as the 1994 study) ${ }^{19}$ and a study conducted between August 2006 and January 2007 (referred to as the 2006 study). ${ }^{20}$

Continuous variables are presented as the mean and $\mathrm{SD}$, and categorical variables are presented as absolute and relative frequencies. To compare continuous variables with a normal distribution, analysis of variance was used for more than two samples, and Student's t-test was used 


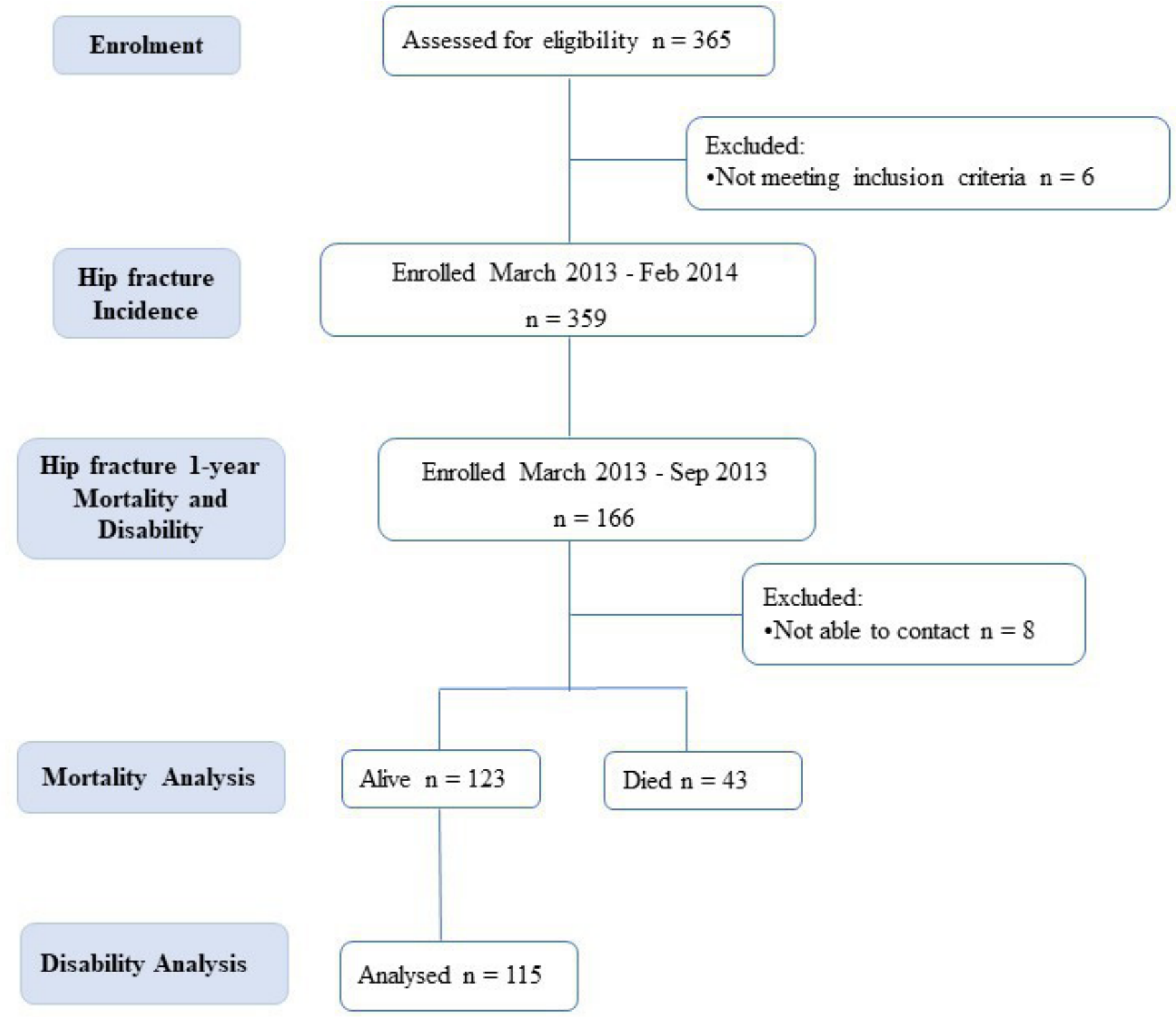

Figure 1 Flow diagram of the study design.

for two samples; if the distribution was not normal, the Kruskal-Wallis test or the Mann-Whitney U test was used. To compare categorical variables, the $\chi^{2}$ test was used. The incidence trends of fractures in the different periods were compared using a univariate generalised linear model.

Multiple logistic regression analyses were also performed with the dependent variables of in-hospital mortality and mortality during the follow-up year. The independent variables were those showing significant associations with mortality in the univariate analysis. A stepwise forward method was used to select the variables.

The statistical analyses were performed with SPSS V.22.0 and EpiInfo 7. The results were considered significant if $\mathrm{p}<0.05$.

\section{RESULTS}

Incidence of hip fractures and patient demographics

During the study period, 365 hip fracture patients were treated. We excluded three patients with periprosthetic fractures, two with pathological fractures and one with a fracture associated with a high impact trauma. Ultimately, 359 fractures were considered osteoporotic. In the population $\geq 50$ years old, this corresponds to an overall incidence of 228 per 100000 individuals/year (95\% CI 204.5 to 251.6), and the incidence was higher in women at 313.1 per 100000 women/year (95\% CI 275.8 to 350.4 ) than in men at 125 per 100000 men/year (95\% CI 99 to 151).

Table 1 shows the characteristics of the men and women with osteoporotic hip fractures. Women had a higher body mass index (BMI) and a higher frequency of osteoarthritis and hypothyroidism than men. There were significant differences in the drugs acting on the central nervous system (CNS). There was a history of a 
Table 1 Characteristics of the patients with osteoporotic hip fractures in the 2014 study

\begin{tabular}{|c|c|c|}
\hline Characteristic & $\begin{array}{l}\text { Women } \\
\mathrm{n}=\mathbf{2 7 0}\end{array}$ & $\begin{array}{l}\text { Men } \\
\mathrm{n}=89\end{array}$ \\
\hline Age (years), mean (SD) & $82.7(7.2)$ & $81.2(8.4)$ \\
\hline Body mass index $\left(\mathrm{kg} / \mathrm{m}^{2}\right)$, mean $(\mathrm{SD})$ & $27.6(5.6)$ & $26.0(4.2)$ \\
\hline \multicolumn{3}{|l|}{ Comorbidities* $n(\%)$} \\
\hline Hypertension & $209(77.4)$ & $64(71.9)$ \\
\hline Cardiovascular disease & $147(54.4)$ & $58(65.2)$ \\
\hline Osteoarthritis & $138(51.1) \dagger$ & $22(24.7) \dagger$ \\
\hline Dyslipidaemia & $95(35.2)$ & $30(33.7)$ \\
\hline Dementia & $92(34.1)$ & $25(28.1)$ \\
\hline Diabetes & $86(31.9)$ & $28(31.5)$ \\
\hline Hypothyroidism & $35(13.0) \dagger$ & $4(4.5) \dagger$ \\
\hline Renal failure & $23(8.5)$ & $13(14.6)$ \\
\hline \multicolumn{3}{|l|}{ Drug treatment* $\mathrm{n}(\%)$} \\
\hline Antihypertensive agents & $199(73.7)$ & $64(71.9)$ \\
\hline Drugs acting on the CNS & $189(70.0) \dagger$ & $51(57.3) \dagger$ \\
\hline Proton pump inhibitors & $128(47.4)$ & $52(58.4)$ \\
\hline Antiplatelet agents & $107(39.6)$ & $42(47.2)$ \\
\hline Statins & $69(25.6)$ & $23(25.8)$ \\
\hline Anticoagulants & $56(20.7)$ & $11(12.4)$ \\
\hline Calcium + vitamin D & $36(13.3)$ & $6(6.7)$ \\
\hline Antiresorptive agents & $26(9.6)$ & $3(3.4)$ \\
\hline History of fracture & $121(44.7)$ & $33(36.9)$ \\
\hline History of falls in the previous year & $239(88.4)$ & $75(80.3)$ \\
\hline Circumstances leading to falls & $190(70.3)$ & $61(67.1)$ \\
\hline $\begin{array}{l}\text { Risk of hip fracture } \geq 3 \% \text { according to } \\
\text { FRAX }\end{array}$ & $241(89.4)$ & $60(67.1)$ \\
\hline \multicolumn{3}{|l|}{ Type of fracture, n (\%) } \\
\hline Extracapsular & $165(61.1)$ & $45(50.6)$ \\
\hline Intracapsular & 105 (38.9) & $44(49.4)$ \\
\hline Time to surgery (days), mean (SD) & $5.0(5.3)$ & $5.5(7.8)$ \\
\hline Hospital stay (days), mean (SD) & $10.9(4.8)$ & $11.2(6.0)$ \\
\hline
\end{tabular}

*Had a frequency $\geq 10 \%$ for at least one sex (for this selection, the figures have been rounded to the nearest whole number). $\dagger \mathrm{P}<0.05$.

CNS, central nervous system.

previous fragility fracture after 50 years of age in $46 \%$ of the women and $37 \%$ of the men (and $42.8 \%$ of all cases were major osteoporotic fractures). In all patients, a fall was the precipitating factor leading to the fracture; in over $80 \%$ of the cases, there had been at least one fall in the year before the current episode, and the median was two previous falls/year. Additionally, $69.7 \%$ of patients had circumstances leading to the falls, and there were no significant differences between sexes. The 10 -year probability of hip fracture using FRAX was $\geq 3 \%$ in $84.3 \%$ of patients at the time of the fracture. Few patients - even fewer men- had received treatment with calcium and vitamin $\mathrm{D}$ or antiresorptive drugs before the episode of hip fracture. The use of these interventions was also low in those with a history of previous fractures $(15 \%$ for calcium and vitamin D (12.9\% and $16.2 \%$ for men and women, respectively) and $11 \%$ for antiresorptive drugs $(9.7 \%$ and $12 \%$ for men and women, respectively) ). The time to surgery (approximately 5 days) and mean hospital stay (11 days) were similar in both sexes. A total of $44.2 \%$ of the patients were at risk for malnutrition, and there were no obvious differences between sexes.

\section{Changes in the incidence of osteoporotic hip fractures over the last 20 years}

When analysing the global incidence rates in the population $\geq 50$ years of age over these 20 years, we found a progressive increase from 198.7 in 1994, 217.3 in 2006 to 228 in 2014. Figure 2A,B shows the incidence rates of hip fracture according to age and sex. In women (figure 2B), the incidence rate decreased in all age groups between 1994 and 2014, especially in subjects $\geq 85$ years old (from 2430 to 1800 per 100000 women/year). In contrast, the incidence rate of hip fractures in men increased between 1994 and 2014, especially in subjects $\geq 75$ years old (from 1710 to 2141 per $100000 \mathrm{men} /$ year) (figure 2A). The generalised linear model analysis of incidence rates by age and sex throughout the study periods reveals a downward trend in women and rising trend in men, but the trends are not statistically significant.

\section{Complications and in-hospital mortality}

Thirty-nine per cent of patients had some in-hospital complications; the most common complications were necessary blood transfusion (19.5\%), acute coronary syndrome/acute myocardial infarction $(4.7 \%)$ and acute renal failure $(4.5 \%)$. In-hospital mortality occurred in $5.8 \%$ of subjects, and this rate was higher in men $(9.0 \%)$ than in women $(4.8 \%)$. The causes of in-hospital mortality were ischaemic heart disease $(38 \%)$, respiratory failure due to pneumonia (19\%), sepsis of an urinary origin $(19 \%)$, heart failure $(14 \%)$, pulmonary thromboembolism $(5 \%)$ and systemic inflammatory response syndrome secondary to infection of the surgical wound (5\%). Although not statistically significant, there was a distinct increase in the mortality rate across the different periods evaluated over the last 20 years (table 2). The factors associated with in-hospital mortality in the univariate analysis were sex, age, renal failure (defined as a creatinine greater than $1.20 \mathrm{mg} / \mathrm{dL}$ ), use of drugs acting on the CNS, use of statins, malnutrition assessed by the MNA tool, and circumstances leading to falls; in the multivariate model, an age over 85 years old and renal failure were associated with in-hospital mortality (table 3 ).

\section{Disability and overall mortality}

A total of 166 patients who suffered from hip fracture during the first 6 months of the study $(46.2 \%$ of the total patients) were scheduled for an annual follow-up. Of them, 123 were alive after 1 year, and 115 (93.5\%) were successfully contacted. According to the modified Barthel index, $30.4 \%$ of patients were dependent before 
A

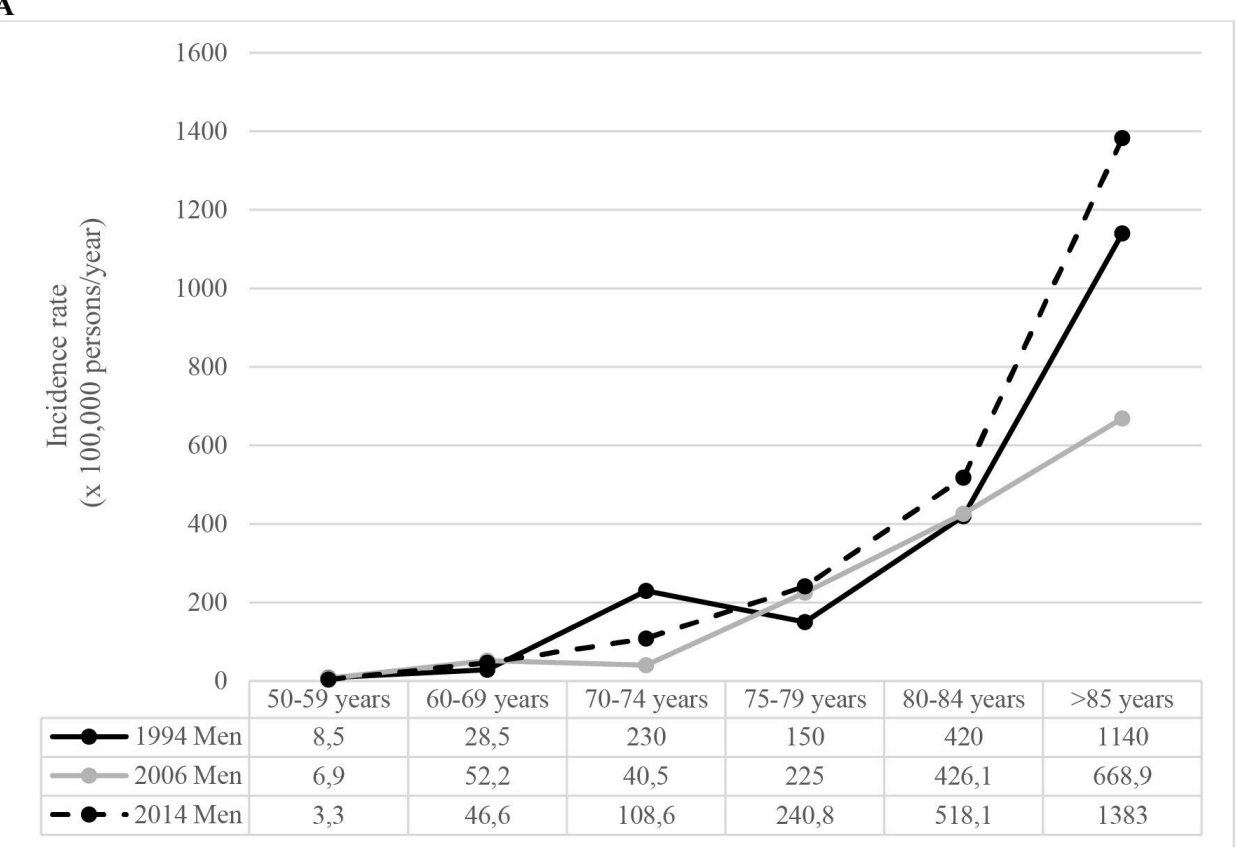

B

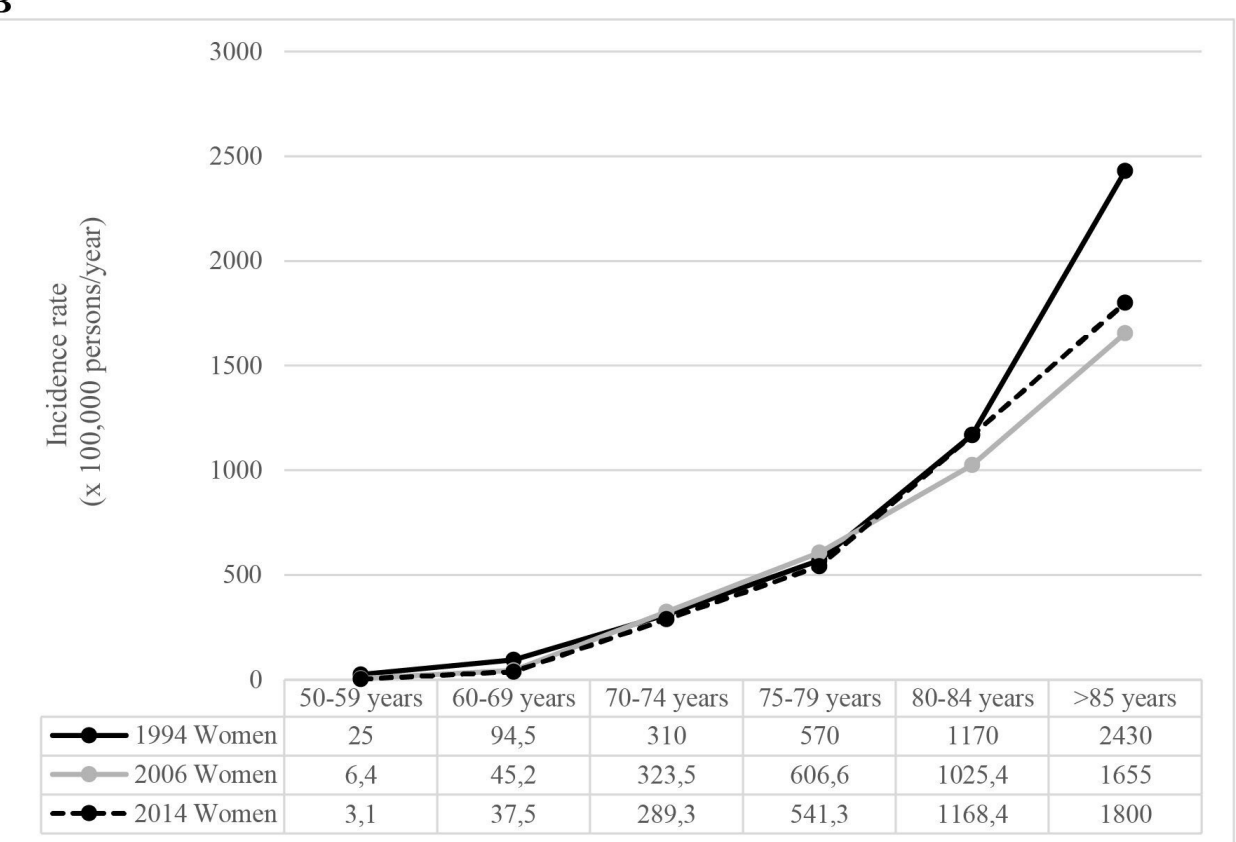

Figure 2 (A) Incidence of osteoporotic hip fractures in men by age in the three studies analysed. (B) Incidence of osteoporotic hip fractures in women by age in the three studies analysed.

Table 2 Evolution of in-hospital mortality in patients with osteoporotic hip fracture

\begin{tabular}{llcl}
\hline & $\mathbf{1 9 9 4}$ & $\mathbf{2 0 0 6}$ & $\mathbf{2 0 1 4}$ \\
\hline Women & 2.3 & 9.0 & 4.8 \\
Men & 6.5 & 17.0 & 9.0 \\
Total & 3.1 & 10.8 & 5.8 \\
\hline
\end{tabular}

All figures are the percentages of patients. the fracture, and this value increased to $65.2 \%$ after the fracture $(p=0.0001)$. The rest of the autonomy/dependency indexes evaluated showed an increase in disabilities (figure 3 ).

Of the 166 patients who suffered a hip fracture in the first 6 months of the study, we were able to contact 158 , and 43 were deceased 1 year after the fracture. This corresponds to $27.2 \%$ mortality rate 1 year after the episode, and the mortality rates were higher in men than in women (37.8\% vs 24\%, $\mathrm{p}=0.097)$. The factors associated with 
Table 3 Factors associated with in-hospital mortality and mortality after the first year in patients with osteoporotic hip fracture

\begin{tabular}{|c|c|c|c|}
\hline Variable & $P$ value & OR & $95 \% \mathrm{Cl}$ \\
\hline \multicolumn{4}{|l|}{ In-hospital mortality } \\
\hline Age ( $\leq 85$ years) & 0.015 & 3.44 & 1.28 to 9.28 \\
\hline $\begin{array}{l}\text { Renal failure (Creatinine } \\
\geq 1.2 \mathrm{mg} / \mathrm{dL} \text { ) }\end{array}$ & 0.011 & 3.31 & 1.31 to 8.37 \\
\hline \multicolumn{4}{|l|}{ Mortality after the first year } \\
\hline $\begin{array}{l}\text { Body mass index }(\geq 25 \mathrm{mg} / \\
\left.\mathrm{m}^{2}\right)\end{array}$ & 0.006 & 3.48 & 1.44 to 8.43 \\
\hline $\begin{array}{l}\text { Renal failure (creatinine } \\
\geq 1.2 \mathrm{mg} / \mathrm{dL} \text { ) }\end{array}$ & 0.011 & 5.07 & 1.45 to 17.68 \\
\hline Plasma proteins ( $\geq 6 \mathrm{~g} / \mathrm{dL})$ & 0.005 & 3.88 & 1.51 to 9.93 \\
\hline
\end{tabular}

overall mortality in the univariate analysis were sex, age, $\mathrm{BMI}$, previous surgery, renal failure, total plasma proteins, dementia, the use of drugs acting on the CNS, use of statins, use of oral anticoagulants, malnutrition evaluated by the MNA tool, circumstances leading to falls, and the existence of complications during hospital admission. In the final multivariate model, the factors associated with overall mortality were a BMI (it was treated as a qualitative variable and a cut-off point of 25 was considered), renal failure and low plasma proteins $(<6 \mathrm{~g} / \mathrm{dL})$ (table 3$)$.

\section{DISCUSSION}

The annual incidence of hip fractures in this health area of Seville in 2014 was high, and these fractures are more common in women than in men. There are sex differences in the incidence trend over the last 20 years, as the incidence decreased in women and increased in men. The in-hospital and overall mortality rates were both higher in men. In both sexes, hip fractures are associated with serious consequences affecting disability and dependence.

The annual incidence of osteoporotic hip fractures in subjects aged $\geq 50$ years ( 228 cases per 100000 individuals) is higher than that reported in other regions in $2013^{21}$ and the overall rate in Spain in 2012 using the minimum basic data set (150 cases per 100000 individuals $)^{8}$ but is lower than that reported in another nationwide study also using the minimum basic data set. ${ }^{7}$ However, our results are similar to those reported by Aguilar del Rey et al in Andalusia from 2000 to 2010, which were 149 and 405 cases per 100000 individuals in men and women, respectively. ${ }^{12}$ The different results may be due to different data

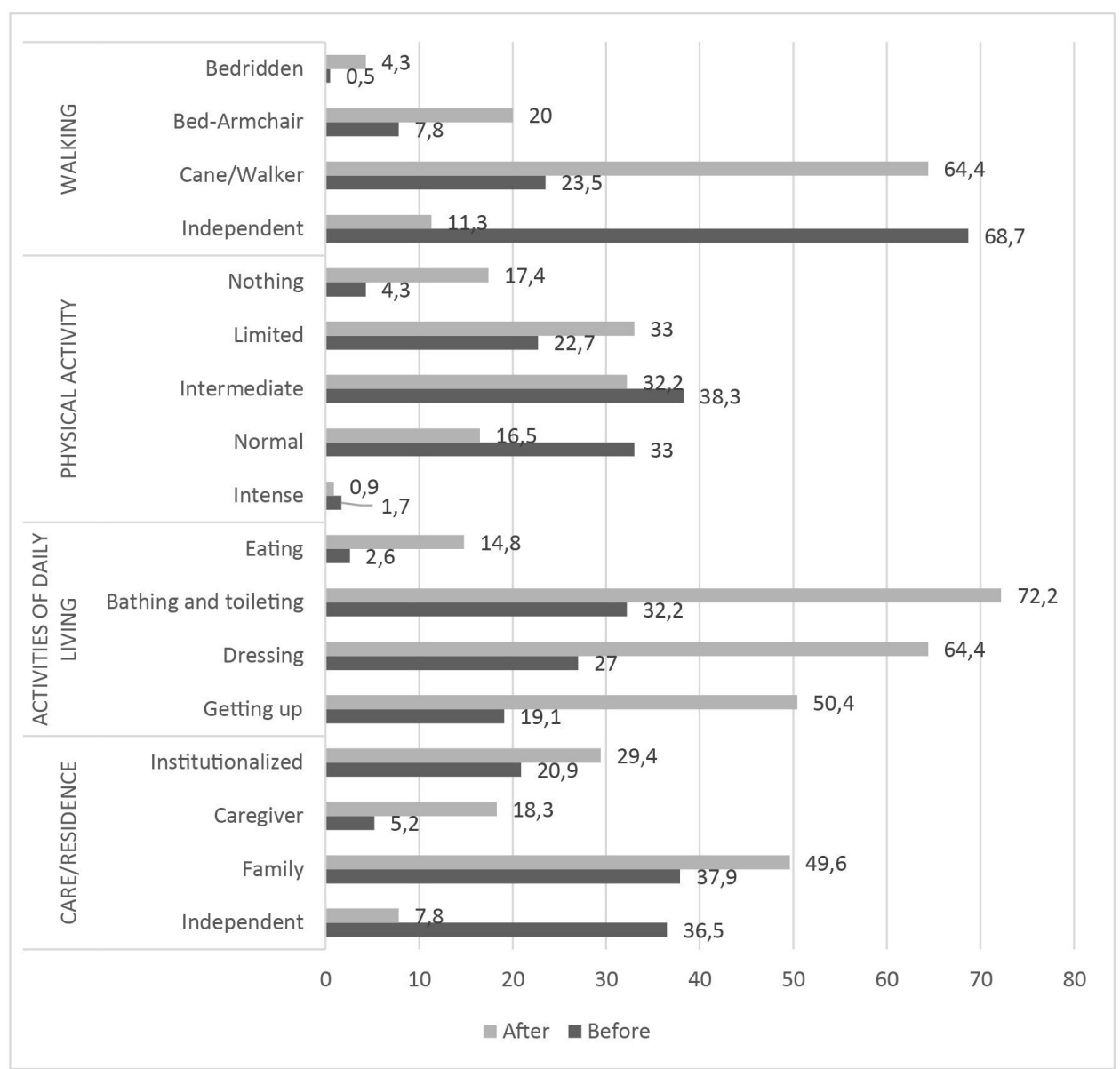

Figure 3 Evolution of autonomy and dependence 1 year after osteoporotic hip fracture. 
collection methods. Our study, unlike those mentioned above, was prospective; we obtained summary information from the patient directly or from family members if necessary. Additionally, our study included a case definition that is somewhat more restrictive than that of most of the other studies. However, there are important differences among the different geographical areas of Spain ${ }^{8}$ and even among the different provinces of Andalusia. ${ }^{12}$ These results are also consistent with the variations in the incidence of hip fracture among different countries worldwide. ${ }^{22}$

The sex differences in incidence rate-which was 2.5 times higher in women-were less marked but followed the same trend as those from studies conducted at the national level or in Andalusia. ${ }^{712}$ More interesting are the different trends in incidence between men and women. Although the trends were not statistically significant, it is relevant that the trend increased in men in the older groups ( $\geq 75$ years) over time, while the incidence of hip fractures in women tended to decrease in all age groups. Similar trends have been reported. ${ }^{7}$ In contrast, other studies have shown a reduction in the incidence of these fractures in both sexes, although the reduction is more marked in women. ${ }^{10}$ The different evolutions between sexes can be explained by the availability and increasing use of effective drugs to treat osteoporosis over the last 20 years. These drugs have been used mostly in women, as women are the most likely candidates to suffer from the disease, and women are diagnosed more frequently than men; therefore, the life expectancy of women increased during this period. ${ }^{23}{ }^{24}$ Internationally, trends in the incidence of hip fractures differ from one country to another; there is a declining trend in women and stable trend in men in Denmark and Austria, ${ }^{25} 26$ while the incidence decreased in both sexes in France and Sweden. ${ }^{27} 28$ In Norway, the incidence is stable, ${ }^{29}$ and it appears to be increasing in other countries such as Korea. ${ }^{30}$ In our health area, since 1998, patients with risk factors for osteoporosis have been managed in a protocolised manner for evaluation, diagnosis and treatment, and since 2003, the recommendations of the Clinical Practice Guideline on postmenopausal osteoporosis for the prevention of fractures have been followed, ${ }^{31} 32$ so we would expect a reduction in the incidence of hip fractures, although we must consider other factors, such as poor therapeutic adherence or the birth cohort effect, which could account for the lack of the reduction in incidence. ${ }^{33} 34$

The present study was carried out in a Caucasian population. Although during these 20 years, the foreign population in this region has increased from $1.2 \%$ to $7.8 \%$, this shift occurred in the young population and did not affect those over 50 years of age. Therefore, we do not consider that the results on the evolution of the incidence of hip fractures are affected by changes in the characteristics of the population in terms of race and ethnicity in this period.

The likelihood of missing cases is low, given that fractures in the population from this health area are only treated in this reference hospital. Although the possibility exists, we consider that the impact would not be very relevant to assessing the evolution of the incidence rate over 20 years.

The sex differences observed in some clinical characteristics (eg, BMI and comorbidities) may reflect the usual differences between the two sexes, ${ }^{35}$ regardless of whether the subjects had a hip fracture. Some factors may partially explain the increase in osteoporotic fractures in men, such as men taking fewer preventive measures than women, possibly owing to sex bias in the care provided to hip fracture patients. ${ }^{36}$ The impact of hip fracture on patient function and dependence is high. In our study, there was an approximately $35 \%$ increase in the number of dependent patients after hip fracture, and $30 \%$ of the patients could no longer live independently and also showed limitations in walking and activities of daily living. These results are consistent with those reported in the literature. Thus, according to a recent meta-analysis, only $40 \%-60 \%$ of patients recover their functional mobility and ability to perform key daily living activities, and $20 \%-60 \%$ require help for tasks related to self-care $1-2$ years after the fracture. ${ }^{37}$ This highlights the importance of rehabilitation in these patients to achieve a state of well-being after fracture by improving their functional capacity and independence. ${ }^{38}$

The overall in-hospital mortality rate was $5.8 \%$, and this rate was higher in men than in women $(9.0 \%$ vs $4.8 \%)$. These results are similar to those reported by other authors. ${ }^{10}$ Although there have been significant variations in these values since 1994, with a striking increase in 2006 that declined again in 2014, the incidence rates tended to generally increase in both sexes, although more markedly in men. The results of a national study also show similar changes between the 1997-2000 and 2007-2010 periods, although the reductions were nearly identical in both sexes. ${ }^{7}$ The overall mortality rate of $27.2 \% 1$ year after the fracture-which included a $37.8 \%$ mortality rate in men and $24 \%$ mortality rate in womenwas comparable to that in other locations in our region. ${ }^{39}$ Worldwide figures are highly variable, ranging from $8.4 \%$ in Sweden ${ }^{40}$ to $24.5 \%$ in a meta-analysis study by $\mathrm{Hu}$ et $a l^{41}$ There are no previous studies in our area with which to compare our trend data during these years. In this sense, the results in other countries show different trends, including an increase in Taiwan, ${ }^{42}$ a decrease in the $\mathrm{UK}^{43}$ and in Denmark ${ }^{26}$ and no change in Sweden. ${ }^{28}$ We included the treatment received as an explanatory variable for 1 year mortality, but we did not find an association. The factors associated with in-hospital mortality in our analyses were age and renal failure; the factors associated with overall mortality were a BMI $<25 \mathrm{~kg} /$ $\mathrm{m}^{2}$, renal failure (plasma creatinine $\geq 1.20 \mathrm{mg} / \mathrm{dL}$ ) and low plasma proteins $(<6 \mathrm{~g} / \mathrm{dL})$. Age and BMI are factors known to be associated with mortality in hip fracture patients. ${ }^{44}$ The presence of renal failure in hip fracture patients has been associated with an increased risk of death and prolonged hospital stay. ${ }^{45}$ 
A relevant finding from the present study is the low percentage $(<10 \%)$ of patients being treated with antiosteoporotic drugs, which is even lower in men, despite the high number of patients with a history of fragility fracture, high number of falls and high probability of hip fracture in 10 years in these patients; this agrees with the findings of other authors. ${ }^{46}$

The present study confirms the frequency of falls and the high malnutrition risk-which occurs in up to $44.2 \%$ of hip fracture patients-reported by other authors. ${ }^{47} 48$ Therefore, it is necessary to advocate for protein nutritional supplements ${ }^{49}$ in elderly people in addition to early functional rehabilitation to reduce the high rate of disability observed in this and previous studies. ${ }^{50}$

Our study has several limitations, one of them is the study is that only the cohort of patients evaluated in the first 6 months were followed to estimate mortality and degree of disability. More long-term studies could provide more information on the disease burden of hip fracture. And other is, we did not include the Charlson Comorbidity Index, which could have improved the multivariate analysis of mortality.

In conclusion, our results show a high incidence of osteoporotic hip fracture that is increasing in men while in women is sustaining. Men are associated with a higher mortality than in women. Likewise, these data again demonstrate the need for interventions with primary prevention measures to both generally reduce this incidence rate and reduce the possible sex gaps in these measures. Furthermore, there is room to improve the modifiable factors associated with mortality, such as BMI $<25 \mathrm{~kg} / \mathrm{m}^{2}$, renal failure and low plasma protein sand the available rehabilitation interventions to reduce the disability associated with these fractures.

\section{Twitter Marta M Rey-Rodriguez @MarReyRod and Mercè Giner @Merce Giner}

Contributors All authors meet the ICMJE criteria for authorship. MMR-R and $\mathrm{M}-\mathrm{JM}-\mathrm{G}$ conceived and designed the study, and FG-V and LF-L coordinated the data collection. MAV-G, MG and MAC undertook the analysis, wrote the first draft and revised the manuscript. MMR-R and M-JM-G provided input to the manuscript drafting process. All authors reviewed and approved the final manuscript.

Funding This study was funded by the Research Project of Consejería de Salud, Junta de Andalucía (Spain) (PIN-0092-2016).

Competing interests None declared.

Patient consent for publication Not required.

Ethics approval The study was approved by the Clinical Research Ethics Committee of the Virgen Macarena Hospital (Seville, Spain).

Provenance and peer review Not commissioned; externally peer reviewed.

Data availability statement All data relevant to the study are included in the article or uploaded as online supplemental information. No additional data available, all data relevant to the study are included in the article.

Open access This is an open access article distributed in accordance with the Creative Commons Attribution Non Commercial (CC BY-NC 4.0) license, which permits others to distribute, remix, adapt, build upon this work non-commercially, and license their derivative works on different terms, provided the original work is properly cited, appropriate credit is given, any changes made indicated, and the use is non-commercial. See: http://creativecommons.org/licenses/by-nc/4.0/.

\section{ORCID iDs}

Marta M Rey-Rodriguez http://orcid.org/0000-0003-3756-1656
MA Vazquez-Gamez http://orcid.org/0000-0001-7689-6999

Mercè Giner http://orcid.org/0000-0002-8285-0767

María-José Montoya-García http://orcid.org/0000-0002-4946-6667

\section{REFERENCES}

1 Sambrook P, Cooper C. Osteoporosis. Lancet 2006:367:2010-8.

2 Braithwaite RS, Col NF, Wong JB. Estimating hip fracture morbidity, mortality and costs. J Am Geriatr Soc 2003;51:364-70.

3 Haentjens P, Magaziner J, Colón-Emeric CS, et al. Meta-analysis: excess mortality after hip fracture among older women and men. Ann Intern Med 2010;152:380-90.

4 Haentjens P, Autier P, Barette M, et al. The economic cost of hip fractures among elderly women. A one-year, prospective, observational cohort study with matched-pair analysis. Belgian hip fracture Study Group. J Bone Joint Surg Am 2001;83:493-500.

5 Kanis JA, Odén A, McCloskey EV, et al. A systematic review of hip fracture incidence and probability of fracture worldwide. Osteoporos Int 2012;23:2239-56.

6 Fernández-García M, Martínez J, Olmos JM, et al. Review of the incidence of hip fracture in Spain. Rev Osteoporos Metab Miner 2015;7:115-20.

7 Azagra R, López-Expósito F, Martin-Sánchez JC, et al. Changing trends in the epidemiology of hip fracture in Spain. Osteoporos Int 2014;25:1267-74.

8 Etxebarria-Foronda I, Arrospide A, Soto-Gordoa M, et al. Regional variability in changes in the incidence of hip fracture in the Spanish population (2000-2012). Osteoporos Int 2015;26:1491-7.

9 Hernández JL, Olmos JM, Alonso MA, et al. Trend in hip fracture epidemiology over a 14-year period in a Spanish population. Osteoporos Int 2006;17:464-70.

10 Esteban RM, Perez-Fernandez E, Crespi-Villarias N, et al. Trends in osteoporotic hip fracture epidemiology over a 17 -year period in a Spanish population: Alcorcon 1999-2015. Arch Osteoporos 2017;12.

11 Pueyo-Sánchez M-J, Larrosa M, Suris X, et al. Secular trend in the incidence of hip fracture in Catalonia, Spain, 2003-2014. Age Ageing 2017;46:324-8.

12 Aguilar Del Rey FJ, Pérez González O, Gonzalez OP. Epidemiology of osteoporotic fractures in Andalusia, Spain, from 2000-2010. Med Clin 2018:150:297-302.

13 Fernández-García M, Martínez J, Olmos JM, et al. Secular trend of the incidence of hip fracture in the world. Rev Osteoporos Metab Miner 2015;7:121-32.

14 Kanis JA, Johnell O, Oden A, et al. FRAX and the assessment of fracture probability in men and women from the UK. Osteoporos Int 2008;19:385-97.

15 Kanis JA, Harvey NC, Johansson $\mathrm{H}$, et al. FRAX update. J Clin Densitom 2017:20:360-7.

16 Vellas B, Villars H, Abellan G, et al. Overview of the MNA-Its history and challenges. J Nutr Health Aging 2006;10:456-63.

17 Liu W, Unick J, Galik E, et al. Barthel index of activities of daily living: item response theory analysis of ratings for long-term care residents. Nurs Res 2015:64:88-99.

18 Kanis JA. Epidemiology of hip fracture in Europe: the MEDOS study. Rev Clin Esp 1991;188:16-19.

19 Llanos RM, Navarro JM, Torrico JMF, et al. Epidemiology of osteoporotic hip fracture in the virgen macarena sanitary area (Seville). Rehabil 1998;2:77-84.

20 Rey M, Montoya MJ, Vázquez MA, et al. Evolution of the incidence of osteoporotic hip fractures in the last two decades in the Macarena health area. REEMO 2008;17:129.

21 Rodríguez NV, Cañal JML, Rodríguez AA, et al. Epidemiology of hip fracture in Gran Canariaa during the five-year period 2007-2011. Rev Osteoporos Metab Miner 2013;5:30-3.

22 Wallace IJ, Botigué LR, Lin M, et al. Worldwide variation in hip fracture incidence weakly aligns with genetic divergence between populations. Osteoporos Int 2016;27:2867-72.

23 Narla RR, Hirano LA, Lo SHY, et al. Suboptimal osteoporosis evaluation and treatment in older men with and without additional high-risk factors for fractures. J Investig Med 2019;67:743-9.

24 Laius O, Pisarev H, Maasalu K, et al. Trends in and relation between hip fracture incidence and osteoporosis medication utilization and prices in Estonia in 2004-2015. Arch Osteoporos 2017;12:48.

25 Concin H, Brozek W, Benedetto K-P, et al. Hip fracture incidence 2003-2013 and projected cases until 2050 in Austria: a populationbased study. Int J Public Health 2016;61:1021-30.

26 Pedersen AB, Ehrenstein V, Szépligeti SK, et al. Thirty-five-year trends in first-time hospitalization for hip fracture, 1-year mortality, 
and the prognostic impact of comorbidity: a Danish nationwide cohort study, 1980-2014. Epidemiology 2017;28:898-905.

27 Briot K, Maravic M, Roux C. Changes in number and incidence of hip fractures over 12 years in France. Bone 2015;81:131-7.

28 Karampampa K, Ahlbom A, Michaëlsson K, et al. Declining incidence trends for hip fractures have not been accompanied by improvements in lifetime risk or post-fracture survival-a nationwide study of the Swedish population 60 years and older. Bone 2015;78:55-61.

29 Polesie S, Sigurdsen U, Bjørgul K. Unchanging incidence of hip fracture in southeastern Norway. Geriatr Orthop Surg Rehabil 2013;4:58-63.

30 YC H, Park YG, Nam KW, et al. Trend in hip fracture incidence and mortality in Korea: a prospective cohort study from 2002 to $2011 . J$ Korean Med Sci 215;30:483-8.

31 Grupo de Trabajo de la Sociedad Española de Investigaciones Óseas Y Metabolismo mineral (SEIOMM). Postmenopausal osteoporosis. Clinical practice guide osteoporosis postmenopáusica. Rev Clin Esp 2003;203:496-506.

32 González Macías J, Guañabens Gay N, Gómez Alonso C, et al. Guías de práctica clínica en La osteoporosis posmenopáusica, glucocorticoidea Y del varón. Sociedad Española de Investigación Osea Y del Metabolismo mineral. Revista Clínica Española 2008;208:1-24.

33 Khosla S, Cauley JA, Compston J, et al. Addressing the crisis in osteoporosis treatment: a path forward. J Bone Miner Res 2017;32:424-30.

34 Samelson EJ, Zhang Y, Kiel DP, et al. Effect of birth cohort on risk of hip fracture: age-specific incidence rates in the Framingham study. Am J Public Health 2002;92:858-62.

35 Foreman KJ, Marquez N, Dolgert A, et al. Forecasting life expectancy, years of life lost, and all-cause and cause-specific mortality for 250 causes of death: reference and alternative scenarios for 2016-40 for 195 countries and territories. Lancet 2018;392:2052-90.

36 Saletti-Cuesta L, Tutton L, Wright J. The relevance of gender in the care of hip fracture patients. Int J Orthop Trauma Nurs 2016;22:3-12.

37 Dyer SM, Crotty M, Fairhall N, et al. A critical review of the longterm disability outcomes following hip fracture. BMC Geriatr 2016;16:158
38 Rasmussen B, Uhrenfeldt L. Establishing well-being after hip fracture: a systematic review and meta-synthesis. Disabil Rehabil 2016;38:2515-29.

39 Ariza-Vega P, Kristensen MT, Martín-Martín L, et al. Predictors of long-term mortality in older people with hip fracture. Arch Phys Med Rehabil 2015;96:1215-21.

40 Abrahamsen B, van Staa T, Ariely R, et al. Excess mortality following hip fracture: a systematic epidemiological review. Osteoporos Int 2009;20:1633-50.

41 Hu F, Jiang C, Shen J, et al. Preoperative predictors for mortality following hip fracture surgery: a systematic review and metaanalysis. Injury 2012;43:676-85.

42 Wu TY, Hu HY, Lin SY, et al. Trends in hip fracture rates in Taiwan: a nationwide study from 1996 to 2010 . Osteoporos Int 2017;28:653-65.

43 Klop C, Welsing PMJ, Cooper C, et al. Mortality in British hip fracture patients, 2000-2010: a population-based retrospective cohort study. Bone 2014:66:171-7.

44 Vosoughi AR, Emami MJ, Pourabbas B, et al. Factors increasing mortality of the elderly following hip fracture surgery: role of body mass index, age, and smoking. Musculoskelet Surg 2017;101:25-9.

45 Porter CJ, Moppett IK, Juurlink I, et al. Acute and chronic kidney disease in elderly patients with hip fracture: prevalence, risk factors and outcome with development and validation of a risk prediction model for acute kidney injury. BMC Nephrol 2017;18:20.

46 Vázquez FL, Bonis J, Cerezo VB, et al. Prevention of osteoporotic fracture in Spain: use of drugs before and after a hip fracture. Rev Osteoporos Metab Miner 2015;7:54-62.

47 Balogun S, Winzenberg T, Wills K, et al. Prospective associations of osteosarcopenia and osteodynapenia with incident fracture and mortality over 10 years in community-dwelling older adults. Arch Gerontol Geriatr 2019;82:67-73

48 Kramer IF, Blokhuis TJ, Verdijk LB, et al. Perioperative nutritional supplementation and skeletal muscle mass in older hip-fracture patients. Nutr Rev 2019;77:254-66.

49 Harrison SJ, Messner J, Leeder DJ, et al. Are albumin levels a good predictor of mortality in elderly patients with neck of femur fractures? $J$ Nutr Health Aging 2017;21:699-703.

50 Wang $\mathrm{Y}$, Wang $\mathrm{M}$, Chen $\mathrm{H}$, et al. Early out-of-bed functional exercise benefits elderly patients following hip fracture: a retrospective cohort study. Tohoku J Exp Med 2018;246:205-12. 